Journal of Research in Interprofessional

Practice and

Education

Vol. 5.2

July 2015

\title{
Sixteen Months "From Square One": The Process of Forming an Interprofessional Clinical Teaching Team
}

\author{
Eileen M. McKinlay, MA(App), RN; Peter A. Gallagher, PhD, RN; \\ Lesley A. Gray, MPH, MSc, FFPH; Christine L. Wilson, BComm, DipBus; \\ \& Susan R.H. Pullon, MPHC, FRNZCGP
}

\begin{abstract}
Background: Descriptions of interprofessional education (IPE) programs and teacher competencies exist, but limited research has been undertaken about the process of IPE teaching team formation. This research project examined how pedagogically naïve clinicians of different disciplines initially formed an IPE teaching team.

Methods and Findings: A case study approach was undertaken with data collected over the first sixteen months of an IPE program. Data included: audio recordings, transcripts, and field notes from nine individual teacher interviews, two teaching team focus groups, five student focus groups, and eight summary reports. Data analysis using a grounded theory constant comparison approach revealed themes relating to the formation, development, and evolving sophistication of the teaching team from functioning, to co-ordinating, to co-operating, and finally to collaborating. These stages were influenced by four external factors: remote rural context, Hauora Māori principles, personal attributes, and teacher development.

Conclusions: Formation of interprofessional clinical teaching teams requires educational preparation, time learning to work with each other, and trust development, with a number of local contextual factors influencing this process. Teaching team formation paralleled Wegner's Community of Practice model where shared vision supported the adoption of an increasingly complex IPE pedagogy.
\end{abstract}

Keywords: Interprofessional relations; Staff development; Remote rural; Education

\section{Journal of Research in Interprofessional Practice and Education (JRIPE) \\ Vol. 5.2 \\ (C) 2015 \\ Corresponding author: Eileen M. McKinlay. Email: eileen.mckinlay @otago.ac.nz}

\section{Introduction}

In the healthcare sector interprofessional education (IPE) has growing support [1-3]. A central argument for IPE is the imperative that health professionals need to work together in clinical practice; therefore, students at both undergraduate and postgraduate levels should have opportunities to learn together [4].

However, in New Zealand although some IPE postgraduate initiatives exist [5-8], there are few opportunities for IPE at the undergraduate level [7,9-12]. Significant structural changes to the organization, funding, and delivery of health professional 
2

Forming an Interprofessional Team

McKinlay, Gallagher, Gray, Wilson, \& Pullon

Journal of Research in Interprofessional Practice and Education

Vol. 5.2

July 2015 education to enable IPE is unlikely to happen in the short term [13], and instead an incremental introduction of undergraduate IPE is to be expected.

This incremental approach acknowledges that many, if not most, health professional teachers, particularly those who are primarily clinicians (clinical teachers), have very little day-to-day contact with health professional students other than with those from their own profession, let alone contact with teachers of other health disciplines. Because of this there needs to be a clear process to identify and support the development of those interested in teaching IPE programs but who currently teach in separate undergraduate programs. These teachers are likely to have significant individual IPE learning needs; to attain teaching competencies and form effective teaching teams their needs must be identified and addressed [14,15 ].

The necessary competencies for IPE teachers in general have been described by Freeth et al. [16] and subsequently endorsed and expanded upon by others [4,17-19]. However, descriptions of existing IPE programs include only limited detail about the numbers or discipline composition of IPE teachers involved in classroom, clinical, or small-group delivery. From this it seems faculty-employed staff are usually involved in delivering IPE programs rather than clinical teachers [20-22]. Although IPE relies on teachers from different disciplines, pragmatically it appears that IPE is more commonly carried out by a single teacher (sometimes with a mentor)[22] or pairs of teachers [23] and less commonly by teams of teachers.

Theory has been developed about how teams form [24,25], including the often cited Tuckman model proposing the following group processes: forming (leader directs), storming (cliques form/members vie), norming (decisions are becoming collaborative), performing (team adopts shared strategic vision) [26]. Team formation principles have also been applied to healthcare teams [27,28], but the latter is usually in relation to the delivery of clinical care [29] and not specific to IPE teaching teams, where it is possible a different process may exist. Although IPE teaching teams are mentioned, there does not appear to be any specific research describing the process of teacher team formation, particularly teams of clinical teachers.

Detail about IPE teacher team composition and formation would seem useful for educational governance or faculty new to IPE in order for them to reproduce the process. Furthermore, identifying the stages of likely team formation would allow those involved to chart team development progress and enable planning for timely support and professional development opportunities.

The focus of this research project was to describe specifically how clinicians of different disciplines initially formed an IPE teaching team.

\section{Context}

The Tairāwhiti Interprofessional Education (TIPE) program is offered by the University of Otago in collaboration with the Eastern Institute of Technology and the Tairāwhiti District Health Board. The Tairāwhiti District Health Board covers a remote rural region in New Zealand with a population of around 45,000 [30]. The region has a large rural catchment and the highest relative numbers of indigenous peoples, Māori, per District Health Board region in New Zealand. 
Forming an Interprofessional Team

McKinlay, Gallagher, Gray, Wilson, \& Pullon

Journal of Research in Interprofessional Practice and Education

Vol. 5.2

July 2015
The TIPE program is a stand-alone rotational program of five weeks' duration and is delivered five times a year. Each program delivery has between 10 and 12 final year students from six different disciplines: dentistry, dietetics, medicine, nursing, pharmacy, and physiotherapy. The students travel relatively long distances (minimum $100 \mathrm{~km}$ and maximum $800 \mathrm{~km}$ ) from their respective campuses. They live together in shared accommodation for the duration of the program.

To support student learning, local clinicians, one from each profession, were appointed around four months in advance of the program start date to work a halfday a week (0.1 FTE) as an IPE teacher. As part of a teaching team they are involved in all aspects of the IPE program. Although most individually had previously supervised students of their own discipline, only one had previously worked in a classroom setting.

The program is predominantly experiential in nature. Clinical activities are a combination of time within their own discipline's clinical settings and time within the other disciplines' clinical settings. Classroom teaching, no more than 15 percent of the time, involves at least two and often more teachers facilitating on a rotating roster.

\section{IPE teacher team development}

At best, university educational support for the teaching team is $330 \mathrm{~km}$ (an eighthour drive) from the university campus in Wellington. Mindful of the distance between the university campus and the delivery site, there was an imperative from the outset to develop the clinical teachers as an independent, competent, and self-sustaining teacher team.

In pursuit of that goal, the university academic support team provided intensive initial support through the development of teaching, learning, and assessment frameworks; resource development; and a preliminary two-day onsite faculty-delivered induction to IPE and adult teaching principles. Because of distance constraints, it soon became apparent that conventional approaches to ongoing staff development (regular and frequent workshops, online teaching-support modules, classroombased recurrent sessions) would be unrealistic. Instead, support from the university academic support team was provided at the teaching team's request, including visits from individual faculty members, presentations on different topics, coaching, and moderation of student assessment.

\section{Methods}

The TIPE program is funded by a government agency, Health Workforce New Zealand (HWNZ). This meant that many aspects of the program were subject to a broad and systematic research evaluation for which ethical approval was granted by the Ethics Committee of the University of Otago.

A case study approach was chosen because it provides a method to report on an organization, program, or process, or a combination of these events [31-33]. This approach generally uses a number of qualitative data sources to gather a range of perspectives to enable assessment of whether triangulation of views occurs [34]. Case study was thought most suitable as it would account for contextually situated real-life 


\section{JRIPE}

4

Forming an Interprofessional Team

McKinlay, Gallagher, Gray, Wilson, \& Pullon
Journal of Research in Interprofessional Practice and Education

Vol. 5.2

July 2015 events, including the impact on teachers' views at defined points of time, relationships between teachers, and identify any changes occurring over the data collection time.

The independent evaluation was undertaken by a staff member (PG) not involved in the teaching of the TIPE program and located at the Wellington campus site. The qualitative data were collected from the teaching team and students. Data collection started from July 2012, four months after the program lead-in and two months after the program commenced, and continues to the present. In this article, data analysis covers the first 16 months of the program.

Data were gathered in the form of summary reports, audio recordings of individual and focus group interviews, transcripts, and in some instances field notes when individuals were uncomfortable being audio recorded. Figure 1 summarizes the type and time collection of data.

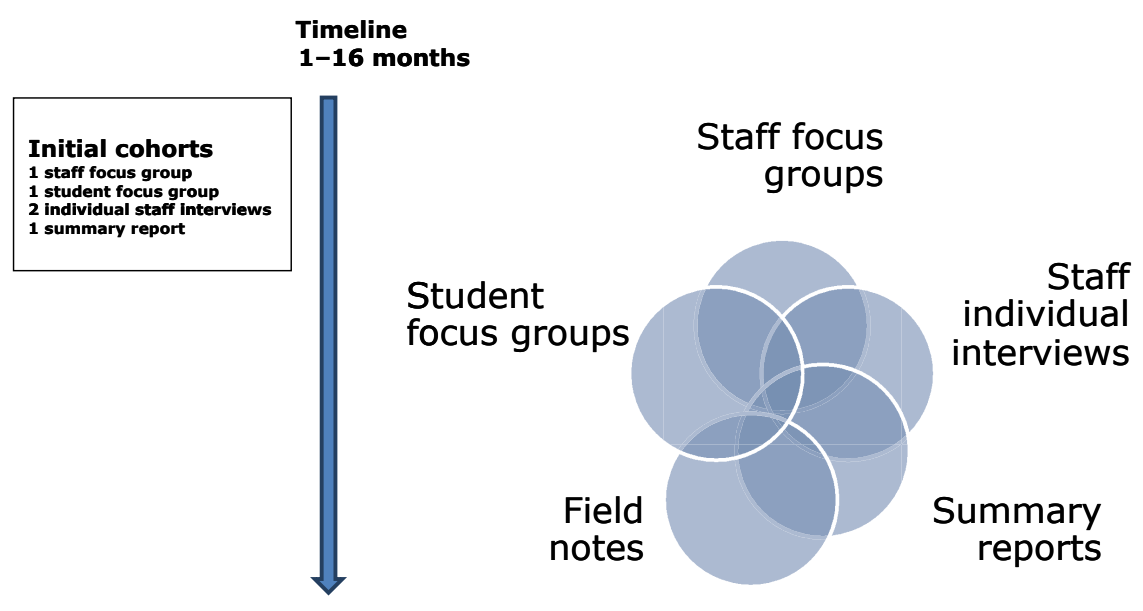

Figure 1. Data collection sources

In total there were audio recordings, transcripts, and field notes from nine individual interviews with teachers and two focus groups with the entire teaching team. The trigger questions for the teachers' focus groups and individual interviews are presented in Table 1. In addition, and to establish if the enthusiasm expressed by the teachers in the interviews translated to the quality of their performance seen through the eyes of students, five focus groups comprising the students who engaged in each rotation were conducted. Eight summary reports synthesized the various viewpoints, and as a method of validation these summary reports were shared with the entire teaching team.

Table 1. Teacher: Interview question zones (focus groups and individual interviews) 


\section{JRIPE}

5

Forming an Interprofessional Team

McKinlay, Gallagher, Gray, Wilson, \& Pullon

\section{Data analysis}

Data from transcripts, field notes, and summary reports were analyzed using a modified grounded theory [35] approach implicit in case study method. Each type of datum (focus group, individual interview, field note, and summary report) was compared with other data types for range and similarity or difference in responses and explicitly taking account of the changing timeframes. There was a particular focus in looking at the data from individual teacher interviews compared with focus group teacher data.

By analyzing the data sequentially according to the time period in which they were collected, two of the authors (PG \& EM), by comparison and discussion, discerned common sets of responses that altered over the period of data collection.

\section{Results}

Functioning, co-ordinating, co-operating, and collaborating charted the formation, development, and evolving levels of sophistication of the teaching team over their first sixteen months of IPE teaching (see Figure 2). These levels were influenced by a number of external factors, including: the remote rural context, Hauora Māori principles (the social and clinical practices associated with the wellbeing of a person who is a member of a whanau-family, hapū-subtribe, and iwi-tribe), personal attributes, and teacher development.

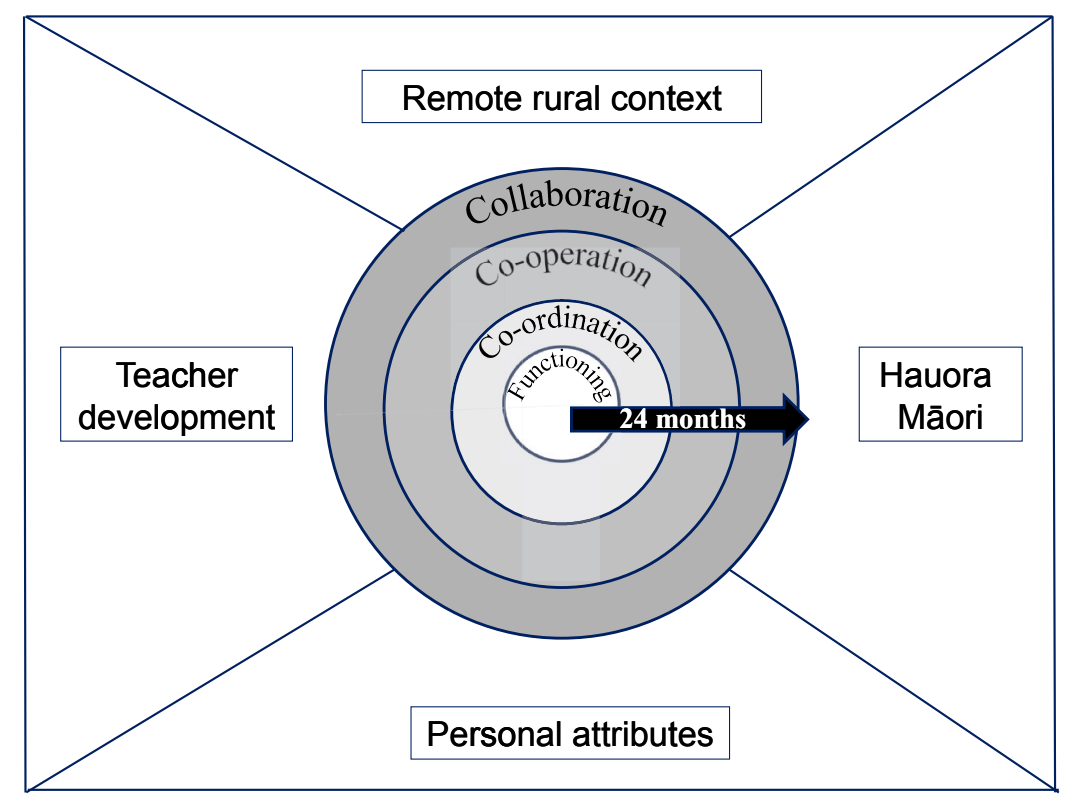

Figure 2. Teaching team development and skill acquisition over 2 years

Journal of Research in Interprofessional Practice and Education

Vol. 5.2

July 2015
The following comment typified the initial uncertainty the teachers felt:

We talk about multidisciplinary teams, but we don't actually see a lot of interprofessional working, and actually it's made us probably 
Forming an Interprofessional Team

McKinlay, Gallagher, Gray, Wilson, \& Pullon
Journal of Research in Interprofessional Practice and Education

Vol. 5.2

July 2015

\section{Journal of Research in Interprofessional Practice and Education}

think more broadly how we can do that [interprofessional education]. (Individual teacher interview, July 2012)

\section{Functioning: Starting to teach}

At the beginning and for the first six months of the TIPE program, the teaching team was largely concerned with simply functioning and getting the program underway.

[Looking back] But I think that last year we were working from day to day and finding our feet and making it up as we went along. (Focus group interview, February 2013)

This was characterized in the interviews by talk about developing the timetable, programming clinical and classroom sessions, and dividing the tasks.

We didn't know how it was actually going to work in practice, and what the nuts or bolts were going to be. (Focus group interview, July 2012)

Discussion about these functional activities was accompanied by some general misconceptions and a lack of a full understanding of IPE.

To start with, there was a little bit of confusion... how was that [interprofessional education] going to work. (Focus group interview, July 2012)

How are we going to cope with lots of students of different disciplines coming in? Are they going to be coming in every day? (Focus group interview, July 2012)

The team members were anxious to prove to themselves and to others that they could get the program up and running: "Got to jump in the deep end" (Focus group interview, July 2012). The four-month lead-in time had not necessarily allowed them to fully develop the skills they felt they needed. These feelings were coupled with a recognition that they had to begin in order to gain greater skills and then use those skills to adapt the program.

Probably right at the beginning I felt quite anxious about it. It all happened very quickly, and suddenly the students were there the next day, and I yeah, probably didn't feel that well prepared, to be honest. (Focus group interview, July 2012)

Despite a perceived lack of skill, even at this very early stage of the program, the individual team members were seen as approachable and supportive by students.

The quality of the teachers is excellent. We are comfortable approaching them to raise concerns and seek clarification. They are very, very supportive of us. (Focus group interview, July 2012)

\section{Co-ordinating: Aligning teaching skills}

As time progressed, individual teachers became more open to sharing ideas for teaching and observing each other's teaching sessions with a cross pollination of 
McKinlay, Gallagher, Gray, Wilson, \& Pullon
Journal of Research in Interprofessional Practice and Education

Vol. 5.2

July 2015

\section{Journal of Research in Interprofessional Practice and Education}

skills and activities. This process assisted both the development of individual teaching skills and cultivated trust among the team members. As a result, between six to twelve months after starting, the teachers adopted a more co-ordinated approach and a clear teaching philosophy evolved through working together. The co-ordinating phase was characterized by working in sequence-each teacher knowing when they are required and what they teach; teachers taught topic areas they knew about.

[Looking back] I think [it's been approached] from a discipline background and trying to give each discipline [teacher] an opportunity to do some teaching, which has been a good way to start. (Focus group interview, February 2013)

The teachers also began to query the usefulness of the unidisciplinary teaching process, recognizing students were making the leaps in learning just through being with each other.

How [do we] make the best use of classroom time and how to make classroom sessions more interactive. (Summary report: teacher and student interviews, October 2012)

\section{Co-operating: Joining teaching skills}

After 12 months of working together, the team described a process of co-operative working whereby they reflected on how they as a group might contribute to the interprofessional learning outcomes. They considered the learning needs of students as an entire group regardless of discipline, particularly those that related to shaping attitudes. It was noticeable that at this point the team started referring to "we" when describing their teaching intentions.

We have tried to get the students talking as much as we possibly can and have them spending a lot more time talking than us, and it has been really successful. (Focus group interview, February 2013)

The team talked of being consistent with all class members irrespective of the student's professional discipline.

We don't let other disciplines get away with [not] doing things. ... So it doesn't [mean] giving somebody an exception because say they're a [dietetics/nursing/medical] student. (Focus group interview, February 2013)

A new focus emerged with the team deciding which educational approaches would best meet the diverse group learning needs.

Well I think we need to somehow get a better balance because it is a program that sets the scene for a better connectiveness between the professions. Isn't it ... I suppose it is in the question of education ... we're talking about a number of different discourses or paradigms. (Focus group interview, February 2013) 
Forming an Interprofessional Team

McKinlay, Gallagher, Gray, Wilson, \& Pullon
Journal of Research in Interprofessional Practice and Education

Vol. 5.2

July 2015

\section{Journal of Research in Interprofessional Practice and Education}

\section{Collaborating: Teaching interprofessionally}

After 13 months a new discipline (and teacher) joined the IPE program and one existing teacher left. These changes did not appear to cause great disruption. The core team at this point was firmly established and described group barriers being broken down with greater trust, a desire to collaborate, and an ability to mentor new staff.

And also the [mixed discipline] teaching team helps to break down those barriers between the different disciplines as well. So I think the biggest thing for setting up the program is having the right team to be able to deliver it. (Individual teacher interview, May 2013)

So I think that's a part of educating about ourselves.... That's a real teamwork exercise, putting yourself in somebody else's shoes. (Focus group interview, February 2013)

Collaboration was evident during the group discussion about fine-tuning the delivery of the program; evaluating the learning outcomes and discerning which team components lead to enhanced learning; and how the components could be altered, improved, and refreshed.

You know, we do that session on the first morning about what their expectations are; and I think more often than not there's a bit of stunned silence. ... Is there a way of having some of their expectations done prior to arrival? (Focus group interview, February 2013)

But I think actually what we maybe need to do is to think what information the students need to have and it doesn't really matter who delivers that information. It's about the students' need ... what we want to achieve out of the sessions ... rather than us coming and delivering what we think might be interesting. (Focus group interview, February 2013)

You get this block [referring to a cohort of students] and then the next block and ... it's trying to keep refreshing our approaches. (Individual teacher interview, June 2013)

The team now explicitly acknowledged the program had a major role in supporting students to develop personal and professional values and, paradoxically, similarly for individual teachers the development of IPE skills. These values and skills were gained through "doing" and reflection combined with the development of tacit knowledge.

It would mean changing the content of some of the sessions we deliver, but I don't see a problem with that. ... to concentrate more on the development of those personal qualities. (Focus group interview, February 2013)

What we're thinking about is better preparing them for what's going to help them as they go into our community. So better prepared for the exposure part. (Individual teacher interview, June 2013) 
9

Forming an Interprofessional Team

McKinlay, Gallagher, Gray, Wilson, \& Pullon

Journal of Research in Interprofessional Practice and Education

Vol. 5.2

July 2015
I think doing is learning... they've learnt a lot without us saying anything. ... some people are locked into the attitude that learning is all about [taught] knowledge. (Focus group interview, February 2013)

\section{Discussion}

Research on development for IPE teaching has largely focused on faculty-taught programs [17,23,36-38] involving single or paired teacher involvement in classroom teaching [4].

The TIPE program offered an opportunity to examine how experienced clinicians, but teacher-naïve, initially formed an IPE clinical teaching team, thus enabling others to support IPE teaching team formation or to monitor progress.

Although the teachers in the teaching team already knew each other as professional colleagues in the care of patients, this did not mean they understood the scope of each other's disciplines or personal skills or how they may function as a team. Our model of functioning - co-ordinating - co-operating - collaborating does not mirror Tuckman's team formation model of forming - storming - norming - performing. The IPE teaching team performed right from the start, perhaps influenced by local loyalty (as employed by the same organization) or a desire to achieve the vision of the IPE program.

Although initially this was a functional educational program with mentoring provided by those more proficient in educational approaches [23], the teaching team soon developed increasingly sophisticated approaches. This involved getting going and functioning, to the sequential co-ordination of skills, to actively co-operating, to jointly teach according to students' learning needs regardless of discipline, and finally, to collaborating to teach interprofessionally. This development phase better matches Wenger's description of a community of practice [39]: "people who share a concern, a set of problems, or a passion about a topic, and who deepen their knowledge and expertise ... by interacting on an on-going basis" [40, p. 4].

The teaching team had a purpose (to deliver an IPE program), an identity (as an IPE team), their respective roles had meaning for them (as IPE teachers), and thus together they were able to develop as a community (an IPE teaching team). These four criteria, seen as central to the establishment of a community of practice $[39,40]$, enabled the team to develop and implement an increasingly complex IPE pedagogy, hallmarked by facilitation. Facilitation focuses less on the teacher's status as expert but on their ability to "enable students to ask the right questions within a group context" $[17$, p. 82] and where interdisciplinary problems or projects are worked on together. In this situation, the IPE teaching team as a whole has worked together to develop this form of facilitation, rather than seeing themselves as individual IPE teachers.

The teaching team has developed to a point where they are equally concerned about all students' learning outcomes and not just the students from their particular discipline. This shift in thinking has been accompanied by the members of the team no longer just teaching subject-specific content, although this still happens to some extent, but facilitating intragroup student discussion on professional values and attitudes. Within these classroom-based sessions there is an increasing recognition that 
10

Forming an Interprofessional Team

McKinlay, Gallagher, Gray, Wilson, \& Pullon

Journal of Research in Interprofessional Practice and Education

Vol. 5.2

July 2015 the teaching team has a role to support: "analysis, debate and discussion" [17, p. 91] but not necessarily to be able to provide the right answers.

An advantage of involving clinicians in IPE teaching is that they can immediately consider and apply new forms of interdisciplinary practice within their clinical environments, thus providing concrete examples of successful collaboration both for themselves and to the students they are teaching. These communities of practice then exist both in an education and clinical environment, thus closing the gap between education and practice [41].

To support development of a community of practice, we advise when selecting individual teachers for an IPE teaching team to consider personality attributes such as personal warmth and team spirit, not just disciplinary content expertise. These personal qualities may overcome the inherent challenges of adapting both to colleagues and to student participants, as well as the historical disciplinary hierarchy and power struggles that Buring et al. note when inducting new IPE teachers [4]. Allowing sufficient lead-in time supports group development as well as skill development. The IPE team leader does not need to be an IPE expert but should have excellent facilitation skills, acknowledge other's skills, and overtly model team respect. When taken together these three aspects appear to strongly influence positive teaching team formation, resulting in a non-hierarchical and facilitative approach evident in teaching interactions and decidedly suited to working with students.

Other external factors may have a substantial bearing when forming an IPE teaching team: the remote rural context, Hauora Māori or similar cultural principles, and teacher development. Collaboration is often a characteristic of health professionals who work in remote, rural locations where interdependence is key to supporting patient health outcomes as well as professional survival [42]. In New Zealand this is supported by the Hauora Māori principle of whanaungatanga (kinship) where, similar to other indigenous cultures, the good of the group is considered more valuable than individual success [43-45]. Because of the rural context, more formal and conventional approaches to provide ongoing professional development may be unsuitable. However, this may replicate for the teaching team the first-hand processes that IPE students experience as they too become an interprofessional group [2]. This enacts Steinert's view that "faculty development programs should model what we are trying to promote" [15, p. 70$]$.

\section{Limitations and strengths}

There are limitations in the generalizability of the study findings. The TIPE teaching team is based in one rural, remote location where, typical of other rural areas, clinicians are self-reliant, resilient, and community focused. They were invited to take part in the IPE teaching team because of their personal and professional qualities and were all keen to take part. Many of the recognized barriers to IPE programs were already overcome [23]. For example, the program was well resourced and it had a full-time administrator. There was a high level of buy-in from the respective organizations and disciplines. The remote immersion model released students from other disciplinary clinical and classroom timetabling obligations. Initial teacher preparation was undertaken and remote teacher support was available. 
11

Forming an Interprofessional Team

McKinlay, Gallagher, Gray, Wilson, \& Pullon

Journal of Research in Interprofessional Practice and Education

Vol. 5.2

July 2015

\section{Conclusion}

It appears that clinical teachers, if specifically chosen and supported, are as well placed as faculty teachers to form IPE teaching teams if they are provided with the necessary and appropriate level of educational support. Contextual factors such as geographical isolation, cultural context, and remote and local backing may positively support IPE teaching team development.

\section{Acknowledgements}

The authors thank the Tairāwhiti interprofessional teaching team for willingly contributing to both the teaching and research on this program. We also thank Health Workforce New Zealand for funding the program and evaluation. Thanks are also due to Ben Darlow for helpful feedback on an earlier draft of this paper and to Sara Bryant for formatting the manuscript.

\section{References}

1. Charles, G., Bainbridge, L., \& Gilbert, J. (2010). The University of British Columbia model of interprofessional education. Journal of Interprofessional Care, 24(1), 9-18.

2. Zwarenstein, M., Reeves, S., Barr, H., Hammick, M., Koppel, I., \& Atkins, J. (2008). Interprofessional education: Effects on professional practice and health care outcomes. Cochrane Database of Systematic Reviews, Issue 1.

3. Abu-Rish, E., Kim, S., Choe, L., Varpio, L., Malik, E., White, A.A., \& Nagasawa, P. (2012). Current trends in interprofessional education of health sciences students: A literature review. Journal of Interprofessional Care, 26(6), 444-451.

4. Buring, S., Bhushan, A., Brazeau, G., Conway, S., Hansen, L., \& Westberg, S. (2009). Keys to successful implementation of interprofessional education: Learning location, faculty development, and curricular themes. American Journal of Pharmaceutical Education, 73(4), Article 60.

5. McKinlay, E., \& Pullon, S. (2007). Interprofessional learning: The solution to collaborative practice in primary care. Nursing New Zealand Kai Tiaki, 13(10), 16-18.

6. McKinlay, E., Pullon, S., \& Visser, J. (2010). Interprofessional postgraduate education: Following the evidence for collaborative health professional practice. Nursing New Zealand Kai Tiaki, 16(10), Suppl 1.

7. Sheehan, D., Ormond, T., \& Wyles, C. (2013). Collaborative practice and interprofessional education and workplace learning. In Higgs, J., Sheehan, D., Baldry Currens, J., Letts, W., \& Jensen, G. (Eds.), Realising Exemplary Practice-Based Education, 223-230. Rotterdam: Springer.

8. Pullon, S., \& Fry, B. (2005). Interprofessional postgraduate education in primary health care: Is it making a difference? Journal of Interprofessional Care, 19(6), 569-578.

9. Boyd, M., \& Horne, W. (2008). Primary health care in New Zealand: Teamworking and collaborative practice-interprofessional learning. Auckland, New Zealand: Waitemata District Health Board.

10. Horsburgh, M., \& Lamdin, R. (2004). Maori health issues explored in an interprofessional learning context. Journal of Interprofessional Care, 18(3), 279-287.

11. Horsburgh, M., Merry, A., Seddon, M., Baker, H., Poole, P., Shaw, J., \& Wade, J. (2006). Educating for healthcare quality improvement in an interprofessional learning environment: A New Zealand initiative. Journal of Interprofessional Care, 20(5), 555-557.

12. Lapkin, S., Levett-Jones, T., \& Gilligan, C. (2012). A cross-sectional survey examining the extent to which interprofessional education is used to teach nursing, pharmacy and medical students in Australian and New Zealand universities. Journal of Interprofessional Care, 26(5), 390-396.

13. Gilbert, J. (2005). Interprofessional learning and higher education structural barriers. Journal of Interprofessional Care, 19(S1), 87-106.

14. Egan-Lee, E., Baker, L., Tobin, S., Hollenberg, E., Dematteo, D., \& Reeves, S. (2011). Neophyte facilitator experiences of interprofesssional education: Implications for faculty development. Journal of Interprofesssional Care, 25(5), 333-338.

15. Steinert, Y. (2005). Learning together to teach together: Interprofessional education and faculty development. Journal of Interprofessional Care, 19(S1), 60-75.

16. Freeth, D., Hammick, M., Reeves, S., Koppell, I., \& Barr, H. (2005). Effective interprofessional education, development, delivery and evaluation. Oxford: Blackwell/CAIPE. 
12

Forming an Interprofessional Team

McKinlay, Gallagher, Gray, Wilson, \& Pullon

Journal of Research in Interprofessional Practice and Education

Vol. 5.2

July 2015
17. Anderson, E., Cox, D., \& Thorpe, L. (2009). Preparation of educators involved in interprofessional education. Journal of Interprofessional Care, 23(1), 81-94.

18. Bray, E. (2008). Interprofessional facilitation skills and knowledge: Evidence from a Delphi study. In Howkins, E., \& Bray, J. (Eds.), Preparing for interprofessional teaching, 27-40. Oxford: Radcliffe Publishing.

19. Wee, B., \& Goldsmith, J. (2008). Preparing faciltators for interprofessional learning. In Howkins, E., \& Bray, J. (Eds.), Preparing for interprofessional teaching, Chapter 5. Oxford: Radcliffe Publishing.

20. Buring, S.M., Bhushan, A., Broeseker, A., Conway, S., Duncan-Hewitt, W., Hansen, L., \& Westberg, S. (2009). Interprofessional education: Definitions, student competencies, and guidelines for implementation. American Journal of Pharmaceutical Education, 73(4), Article 59.

21. Cameron, A., Ignjatovic, M., Langlois, S., Dematteo, D., DiProspero, L., Wagner, S., \& Reeves, S. (2009). An interprofessional education session for first-year health science students. American Journal of Pharmaceutical Education, 73(4), Article 62.

22. Bridges, D., Davidson, R., Odegard, P., Maki, I., \& Tomkowiak, J. (2011). Interprofessional collaboration: Three best practice models of interprofessional education. Medical Education Online, 16(1), 1-10.

23. Silver, I., \& Leslie, K. (2009). Faculty development for continuing interprofessional education and collaborative practice. Journal of Continuing Education in the Health Professions, 29(3), 172-177.

24. Kozlowski, S., \& Bell, B. (2003). Work groups and teams in organizations. In Borman, W., Ilgen, D., \& Klimoski, R. (Eds.), Handbook of psychology (Vol. 12): Industrial and organizational psychology, 333-375. New York, NY: Wiley.

25. Salas, E., Cooke, N., \& Rosen, M. (2008). On teams, teamwork, and team performance: Discoveries and developments. Human Factors: The Journal of the Human Factors and Ergonomics Society, 50(3), 540-547.

26. Tuckman, B. (1965). Developmental sequence in small groups. Psychological Bulletin, 63(6), 384-399.

27. Mosser, G., \& Begun, J. (2014). Understanding teamwork in health care. New York, NY: McGraw-Hill Education.

28. Mickan, S., \& Rodger, S. (2000). Characteristics of effective teams: A literature review. Australian Health Review, 23, 201-208.

29. Bleakley, A. (2013). Working in "teams" in an era of "liquid" healthcare: What is the use of theory? Journal of Interprofessional Care, 27(1), 18-26.

30. Tairawhiti District Health Board. (n.d.). Our population. URL: http://www.tdh.org.nz/about-us /planning-and-funding/our-population/ [July, 17, 2015].

31. Gantley, M., Harding, G., Kumar, S., \& Tissier, J. (1999). Methods of data collection. In Carter, Y., Shaw, S., \& Thomas, S.C. (Eds.), An introduction to qualitative methods for health professionals. London, UK: Royal College of General Practitioners.

32. Yin, R. (2012). Applications of case study research. Thousand Oaks, CA: Sage Publications.

33. Yin, R. (2008). Case study research: Design and methods. Thousand Oaks, CA: Sage Publications.

34. Morse, J. (1991). Approaches to qualitative-quantitative methodological triangulation. Nursing Research, 40(2), 120-123.

35. Glaser, B., \& Strauss, A. (1967). The discovery of grounded theory: Strategies for qualitative research. Chicago, MI: Aldine Publishing Company.

36. Anderson, E., \& Lennox, A. (2009). The Leicester model of interprofessional education: Developing, delivering and learning from student voices for 10 years. Journal of Interprofessional Care, 23(6), 557-573.

37. Oandasan, I., \& Reeves, S. (2005). Key elements for interprofessional education. Part 1: The learner, the educator and the learning context. Journal of Interprofessional Care, 19(S1), 21-38.

38. Oandasan, I., \& Reeves, S. (2005). Key elements of interprofessional education. Part 2: Factors, processes and outcomes. Journal of Interprofessional Care, 19(S1), 39-48.

39. Wenger, E., (1998). Communities of practice, learning, meaning and identity. Cambridge University Press: Cambridge.

40. Wenger, E., McDermott, A., \& Snyder, W. (2002). Cultivating communities of practice: A guide to managing knowledge. Boston: Harvard Business School Publishing.

41. Egan, T., \& Jaye, C. (2009). Communities of clinical practice: The social organization of clinical learning. Health, 13(1), 107-125.

42. Grobler, L., Marais, B.J., Mabunda, S., Marindi, P., Reuter, H., \& Volmink, J. (2009). Interventions for increasing the proportion of health professionals practising in rural and other underserved areas. Cochrane Database Systematic Reviews, Issue 1. Art. No.: CD005314.

43. Royal, C. (2007). The purpose of education: Perspectives arising from Mātauranga Māori. Wellington, New Zealand: Ministry of Education. 


\section{JRIPE \\ Journal of Research in Interprofessional Practice and Education}

13

Forming an Interprofessional Team

McKinlay, Gallagher, Gray, Wilson, \& Pullon
44. Royal, C. (1998). Whare Wänanga: A Pacific tertiary education model for the 21st century. Paper presented at the "Towards the Global University: Strategies for the Third Millennium." University of Central Lancashire, California State University-Fresno and Institut Universitaire de Technologie de Toursin.

45. Ratima, M., Brown, R., Garrett, N., Wikaire, E., Ngawati, R., Aspin, C., \& Potaka, U. (2007). Strengthening Maori participation in the New Zealand health and disability workforce. Medical Journal of Australia, 186(10), 541-543. 